\title{
A clinicopathological review of 100 cases of primary malignant tumours of the liver
}

\author{
R. N. M. MacSWEEN \\ From the University of Glasgow, Department of Pathology, The Western Infirmary, Glasgow
}

SYNOPSIS One hundred cases of primary malignant tumour of the liver coming to necropsy in the period 1900-1969 have been reviewed. The overall tumour incidence was $0.46 \%$ of all necropsies. The overall tumour incidence in hepatic cirrhosis was $12.3 \%$, but the corresponding male and female incidences were 17.5 and $4.4 \%$ respectively. There was no significantly increased tumour incidence in haemochromatosis.

An increasing incidence of primary malignant tumours of the liver has been noted since 1940 and appears to be due to a corresponding increase in incidence of hepatic cirrhosis. Hepatocellular carcinomas outnumbered cholangiocarcinomas by 8 to 1 , were more common in males than females (6 to 1), and in $77 \%$ of cases occurred in cirrhotic livers. Tumours supervened as a complication of macronodular or predominantly macronodular cirrhotic patterns.

Primary malignant tumours of the liver are relatively rare in Europe, the Americas, and Australia, whereas in most parts of Africa and in parts of South East Asia there is a high incidence where they may constitute $30-50 \%$ of all carcinomas (Berman, 1951, 1958; Higginson, 1963; Higginson and Svoboda, 1970). Recent reports suggest an increase in incidence in North America and in some European countries (MacDonald, 1957; Glenert, 1961 ; Patton and Horn, 1964; Ohlsson and Nordén, 1965; Manderson, Patrick, and Peters, 1968).

This marked geographical variation clearly implicates environmental factors in the aetiology of these tumours. Local changes in incidence must therefore be carefully observed. In the present report some epidemiological, clinical, and pathological observations in 100 cases of primary malignant tumours coming to necropsy in this department from 1900 to 1969 are presented. In particular we have examined the incidence of tumours, the relationship to cirrhosis, and the type of cirrhosis in which tumour develops.

\section{Materials and Methods}

The clinical records, necropsy reports, and available histological material on 100 patients with primary malignant liver tumours coming to necropsy at the Western Infirmary, Glasgow, in the years 1900 to Received for publication 8 May 1974.
1969 inclusive have been reviewed. Data from a review of cases of cirrhosis examined during the same period (MacSween and Scott, 1973) will be drawn on where relevant.

Tissue was available in 75 of the 100 cases; in 72 from both tumour and hepatic parenchyma, in two from primary tumour alone, and in one from metastatic tumour alone. In these three last instances the descriptions in the necropsy reports were accepted for the final analysis.

Routine histological staining methods were usedhaemalum and eosin, Masson's trichrome, Gordon and Sweet's reticulin method, Perls' reaction for tissue iron deposits, periodic acid-Schiff (PAS), Best's mucicarmine, and the Rhoda Coomasie's red and yellow method for inclusions.

\section{Results}

\section{CLINICOPATHOLOGICAL REVIEW}

\section{Age, sex, and incidence}

The sex distribution, mean age at death, the tumour/ cirrhosis index, and the incidence of tumours relative to the number of necropsies are summarized in table I.

The number of necropsies, the incidence of cirrhosis, and the incidence of primary liver tumours (with or without cirrhosis) per decade of the review period are summarized in table II. 


\begin{tabular}{lccc}
\hline & Male & Female & Total \\
\hline No. of cases of primary malignant liver tumour & 77 & 23 & 100 \\
Mean age (range) yr & $62(23-99)^{1}$ & $53(9-71)$ & $60(9-99)^{1}$ \\
No. of cases of hepatic cirrhosis & 314 & 205 & $520^{2}$ \\
No. of cases of tumour with cirrhosis & 55 & 9 & 64 \\
Tumour/cirrhosis index (\%) & $17 \cdot 5$ & $4 \cdot 4$ & $12 \cdot 3$ \\
Incidence of tumours relative to no. of necropsies & $100 / 21656(0.46 \%)$ & & \\
\hline
\end{tabular}

Table I Primary malignant liver tumours in the Western Infirmary, Glasgow, 1900-1969

${ }^{1}$ Two cases with no age recorded

${ }^{2}$ One case with no sex recorded

\begin{tabular}{|c|c|c|c|c|c|}
\hline & Necropsies & $\begin{array}{l}\text { Cirrhosis (\% of all } \\
\text { necropsies) }\end{array}$ & $\begin{array}{l}\text { Tumours } \\
\text { with Cirrhosis }\end{array}$ & $\begin{array}{l}\text { Tumours without } \\
\text { Cirrhosis }\end{array}$ & $\begin{array}{l}\text { Total No. of Tumours } \\
\text { (\% of all necropsies) }\end{array}$ \\
\hline $\begin{array}{l}1900-09 \\
1910-19 \\
1920-29 \\
1930-39 \\
1940-49 \\
1950-59 \\
1960-69\end{array}$ & $\begin{array}{l}1857 \\
1540 \\
2264 \\
2609 \\
2914 \\
4751 \\
5630\end{array}$ & $\begin{array}{r}38(2 \cdot 0) \\
35(2 \cdot 2) \\
46(2 \cdot 0) \\
48(1 \cdot 8) \\
61(2 \cdot 1) \\
128(2 \cdot 7) \\
164(2 \cdot 9)\end{array}$ & $\begin{array}{r}5 \\
2 \\
4 \\
4 \\
4 \\
14 \\
31\end{array}$ & $\begin{array}{r}4 \\
1 \\
10 \\
4 \\
4 \\
9 \\
4\end{array}$ & $\begin{array}{r}9(0.48) \\
3(0.19) \\
14(0.62) \\
8(0.31) \\
8(0.27) \\
23(0.48) \\
35(0.52)\end{array}$ \\
\hline Total & 21565 & $520(2.4)$ & 64 & 36 & $100(0.46)$ \\
\hline
\end{tabular}

Table II Primary malignant liver tumours and cirrhosis per decade of the period 1900-1969

\section{Clinical features}

In 11 patients, all males, there was a history of excessive alcohol consumption, and of these nine were shown to have cirrhosis. Two female patients gave a history of jaundice, possibly acute viral hepatitis, eight and 20 years before their terminal illness. In nine patients a clinical and/or pathological diagnosis of haemochromatosis was established. The remaining patients gave no relevant history to suggest a possible cause of tumour or cirrhosis.

A diagnosis of cirrhosis had been made in 11 patients between one and 18 years before death, and in a further 21 cirrhosis was suspected on their terminal admission. A primary hepatic tumour was suspected before death in only nine of the 100 patients. The diagnoses most often made were metastatic tumour in the liver and primary tumour of the extrahepatic biliary system, particularly where jaundice was a major feature.

Abdominal pain was by far the commonest mode of presentation-in 38 of 100 patients. In addition to those 38 in whom it was the primary symptom, pain was also a feature in five patients presenting with ascites and/or oedema, and in the group with clinically diagnosed cirrhosis two patients experienced severe abdominal pain during their terminal illness. Thus in $45 \%$ abdominal pain was a major symptom. In the majority the pain was localized to the right hypochondrium and epigastrium, although in a small number it was generalized and in a few was periumbilical in distribution. Four patients, with no evidence of peptic ulceration, noted that the pain was aggravated by taking food. The other modes of presentation were ascites and/or oedema (13), deterioration in established cirrhosis (11), haematemesis and melaena (10), general malaise/ anorexia/weight loss (7), jaundice (6), metastatic tumour effects (4), intraperitoneal haemorrhage (2), and miscellaneous (9).

In 94 patients in whom an assessment of the duration of symptoms could be made and in whom these symptoms were considered to be primarily related to the intrahepatic neoplasm, the time interval between initial complaint and death was as follows: less than one month, 21 patients; one to three months, 42; four to six months, 23; more than six months, 8. Of the last group two gave a history of recurrent abdominal pain for a period of two years, in one instance accompanied by jaundice, and one (with haemochromatosis) progressively deteriorated over 13 months. In none of these three patients was a diagnosis of malignancy established before death.

\section{Cause of death}

Death resulted from general deterioration/hepatic coma/effects of secondaries in 61 , hepatic coma precipitated by bleeding from oesophageal varices (16), following exploratory laparotomy (13), massive intraperitoneal haemorrhage (2), and from unrelated causes in eight. 
Other associated clinical and postmortem findings Forty-one patients with haemochromatosis came to necropsy over the 70-year period under review and of these nine $(22 \%)$ developed a primary hepatic tumour. Six patients (two female) were diabetics, and of these, three (all male) had diabetes in association with haemochromatosis.

In 14 patients chronic peptic ulcers were present, of which nine were duodenal. In two instances bleeding had occurred from these as a terminal event precipitating hepatic coma. Bleeding from oesophageal varices had occurred in 16 patients, and intraperitoneal bleeding in two, thus giving a $20 \%$ overall incidence of bleeding complications. Oesophageal varices were detected radiologically or at postmortem examination in 28 patients.

Ascites and/or oedema was recorded in 51 patients, and jaundice of varying severity in 42 . Extrahepatic metastatic tumour spread was observed in 47 patients, lymph nodes and lung being the site of predilection.

\section{HISTOLOGY}

Adequate histological material was available for examination in 75 cases, and in 72 of these it was possible to assess the pattern of the hepatic cirrhosis.

\section{Cirrhosis and patterns of cirrhosis}

Cirrhosis was present in 49 of 72 livers $(68 \%)$. Based on the classification of Scheuer (1968), 41 of the 49 livers showed a macronodular cirrhosis, while the remaining eight, though predominantly macronodular, showed some areas in which micronodules were well marked. None showed significant fatty infiltration. Mallory's hyaline was present in two livers, both from patients admitting alcoholic abuse. Thus the features of so-called nutritional or micronodular cirrhosis were conspicuous by their absence.

Most of these cirrhotic livers showed marked continuing hepatitis, manifest by extensive piecemeal necrosis with mononuclear cell infiltrate: lymphocytes predominated but plasma cells were also present. Activity varied, sometimes being more intense near tumour deposits than elsewhere. The hepatitis, particularly near tumour deposits, was often associated with florid ductular proliferation, sometimes involving entire nodules. Assessment of the degree of hepatitic activity (in 41 livers), classified on an arbitrary basis, is summarized in table III.

\section{General tumour morphology}

Sixty-four hepatocellular carcinomas, eight cholangiocarcinomas, two haemangiosarcomas (reported previously by MacSween, Vetters, Rcss,

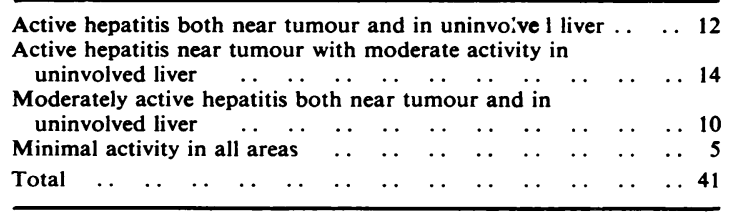

Table III Continuing hepatitis in cirrhotic livers with primary malignant tumours

Ferguson, Johnstone, and Sandison, 1973) and one 'possible' adrenal rest tumour (vi) were examined.

\section{Hepatocellular carcinomas}

These were roughly divisible into trabecular, mixed trabecular/acinar, compact, discrete cell, and anaplastic subgroups. Distinction between the first two groups was not always clear cut, but was based on the absence of acinar differentiation in the trabecular variety.

In a typical trabecular tumour (fig 1) there was considerable variation in trabecular thickness. However, some showed areas of well marked cellular differentiation, in which, apart from some variation of cell and nuclear size, there was a remarkable similarity to normal hepatocytes (fig 2). These tumours usually retained their trabecular appearance in metastases.

Figure 3 shows an example of the mixed group with predominantly a trabecular pattern. In others of this mixed group the acinar pattern was more clearly defined the acini being irregular in shape, variable in size, and containing eosinophilic proteinaceous material (fig 4).

In the compact variety the tumour cells formed fairly uniform sheets, varied only by occasional poorly defined trabeculae. In some the cells were much larger than normal hepatocytes, and the tendency to form diffuse sheets was marked but in some areas of irregular acinar formation were found (fig 5). This tumour had produced cerebral metastases whose histological appearances differed markedly from those in the liver (fig 6). In others of the compact group the cells tended to be smaller with less granular and less dense cytoplasm, but with loose vesicular nuclei in which nucleoli were usually very prominent. Spindle cell areas were sometimes seen in this group (fig 7).

In the discrete-cell variety (fig 8 ) the individual tumour cells closely resembled hepatocytes, having a granular eosinophilic cytoplasm, loose vesicular nuclei with prominent nucleoli, but they were in part separated by a loose fibrous tissue stroma, including a mild infiltrate of mononuclear cells, predominantly lymphocytes.

A small number of tumours consisted largely of 


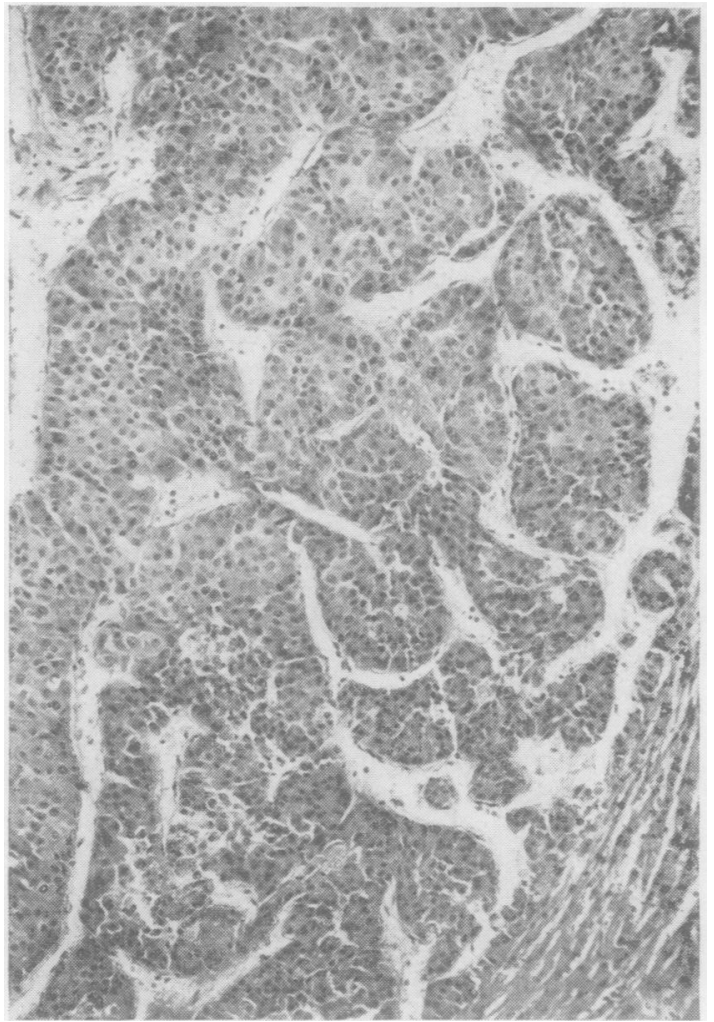

Fig 1

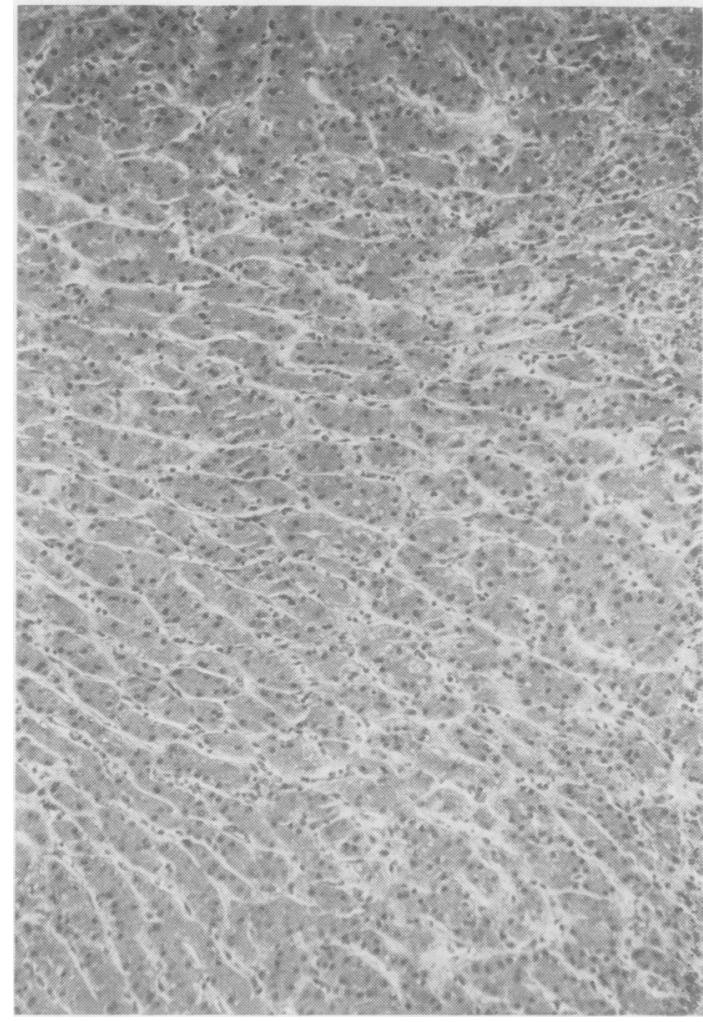

Fig 2

Fig 1 Trabecular hepatocellular carcinoma showing variation in trabecular size and with thin endothelial lined clefts between trabeculae (haematoxylin and eosin $\times 75$ )

Fig 2 Well differentiated trabecular hepatocellular carcinoma (haematoxylin and eosin $\times 75$ )

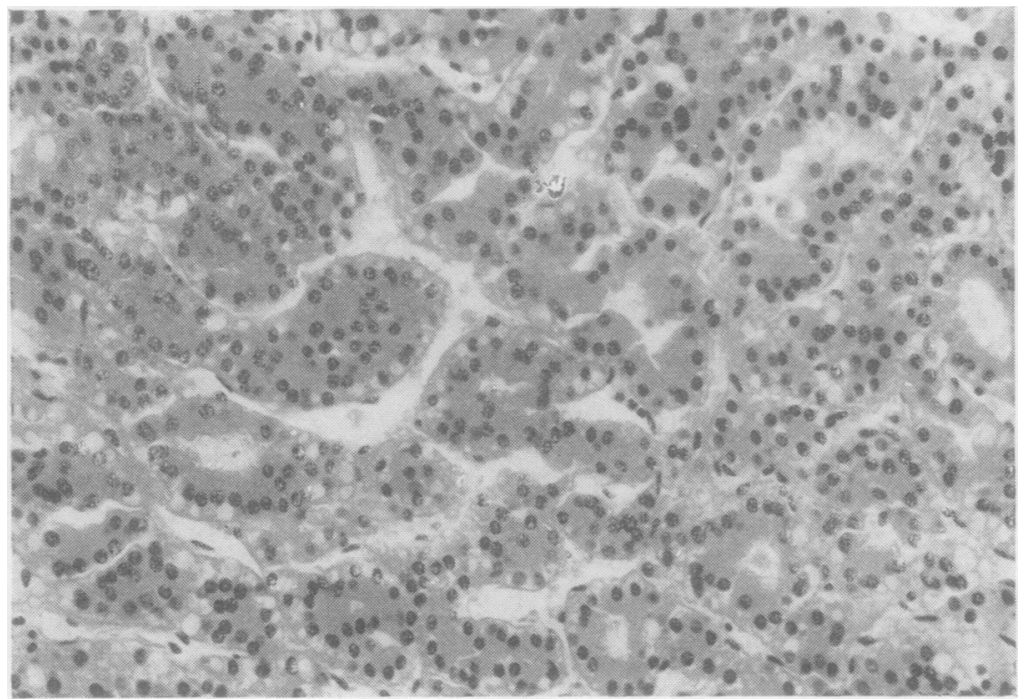

Fig 3 Mixed trabecular/ acinar hepatocellular carcinoma: acinar formation well marked in right lower quarter (haematoxylin and eosin $\times 250$ ) 


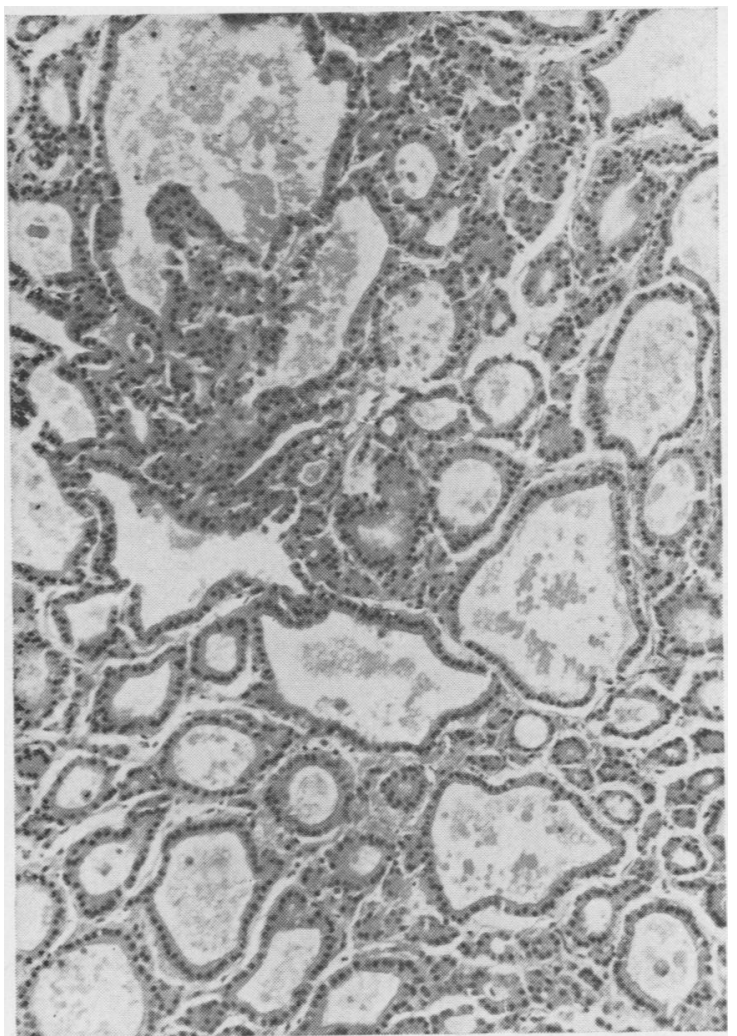

Fig 4 Well defined acinar pattern from a mixed trabecular/acinar hepatocellular carcinoma, the acini containing proteinaceous fluid (haematoxylin and eosin $\times 75$ )

Fig 5 Compact type of hepatocellular carcinoma showing areas:

$A$ with no trabecular formation and with individual cells much larger than normal hepatocytes

$B$ with acinar formation present (haematoxylin and eosin $\times 250$ )

Fig 4
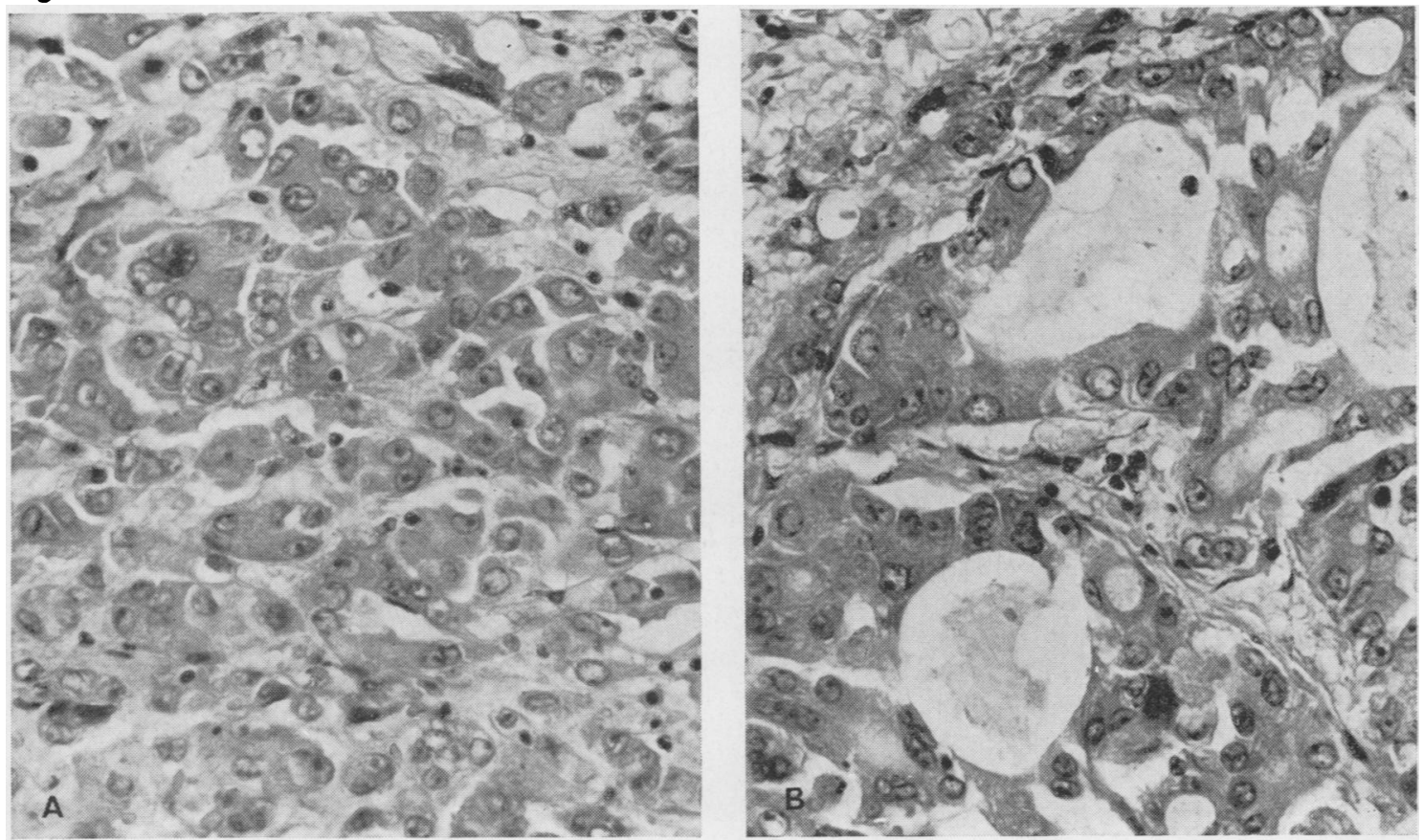

Fig 5 


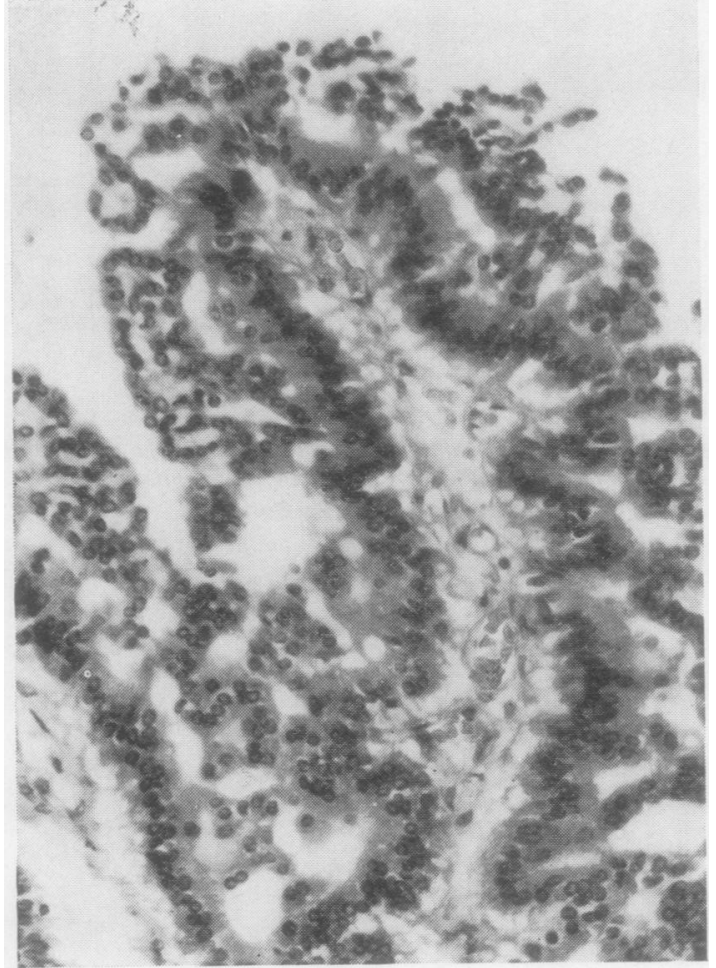

Fig 6 Same case as in fig 5 showing appearance of tumour in metastatic meningeal deposits (haematoxylin and eosin $\times 250$ )

Fig 7 Compact type of hepatocellular carcinoma of a small cell pattern with prominent nucleoli $(A)$ and less well differentiated than that in figure 5. Spindle cell areas also present in this tumour $(B)$ (haematoxylin and $\operatorname{eosin} A \times 300, B \times 250$ )

Fig 6
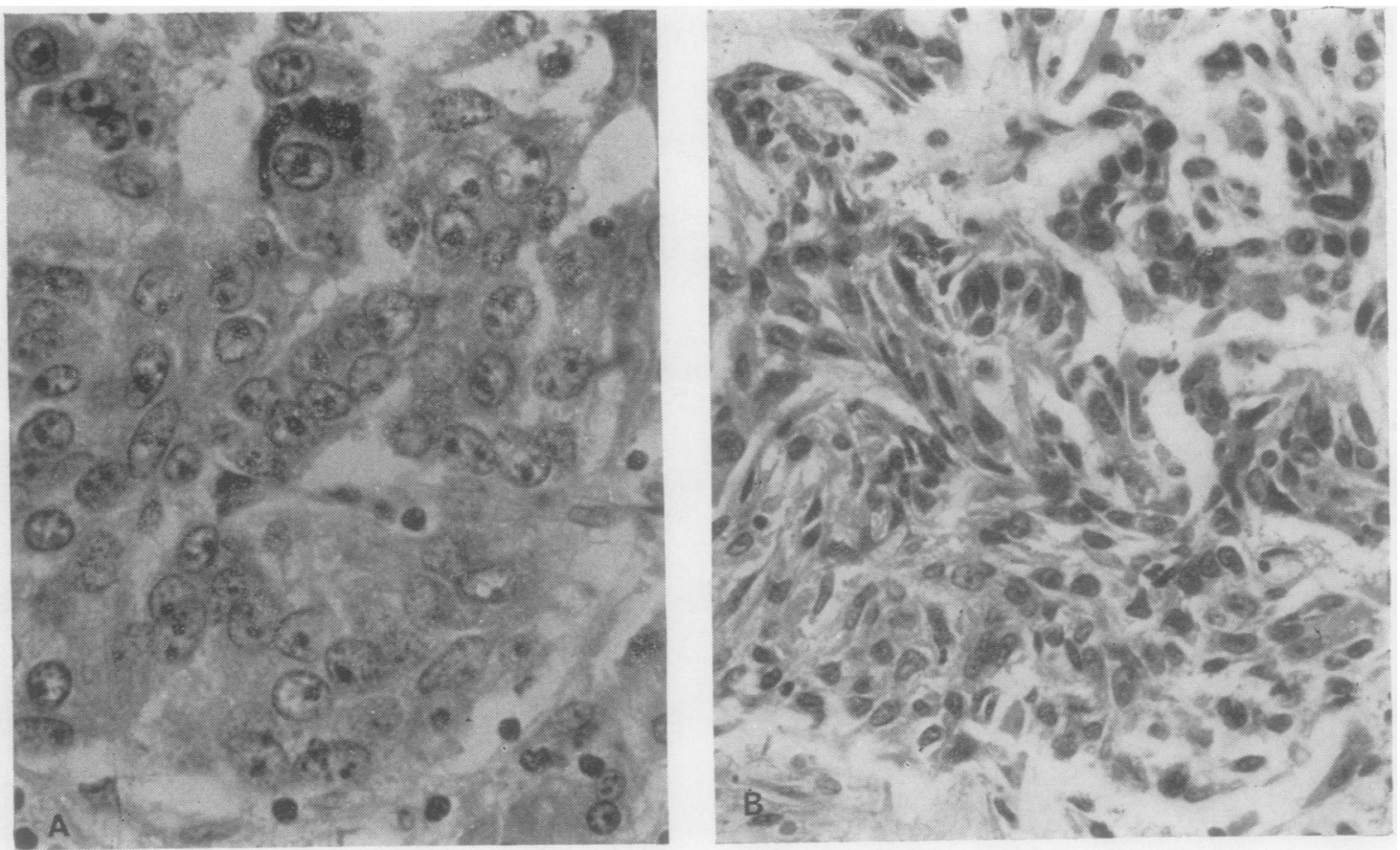

Fig 7 


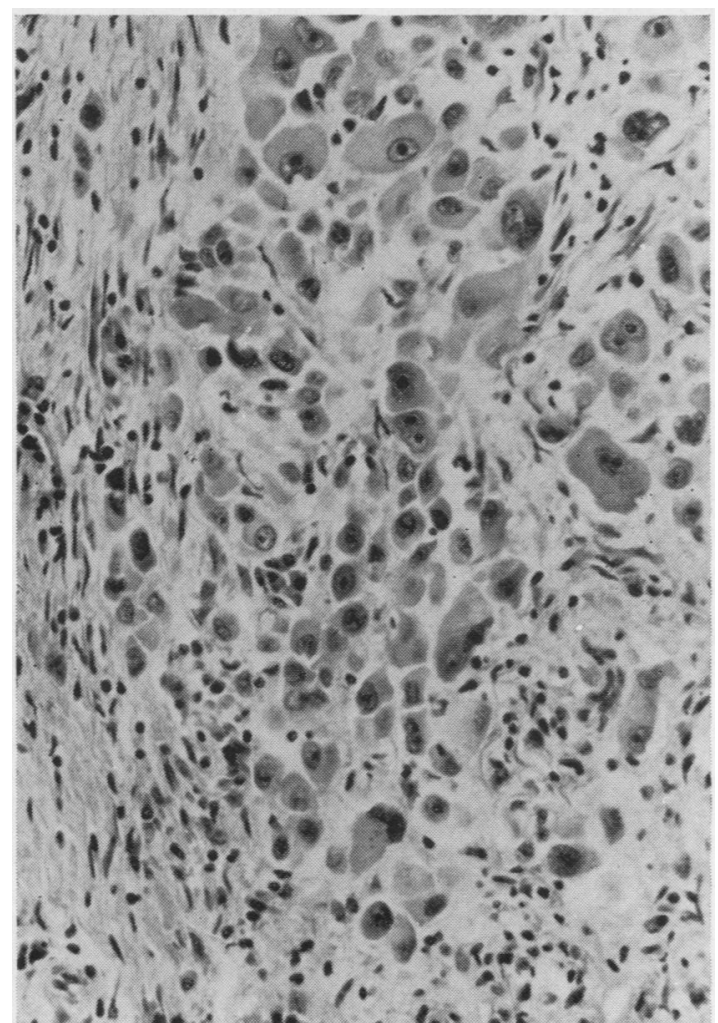

Fig 8

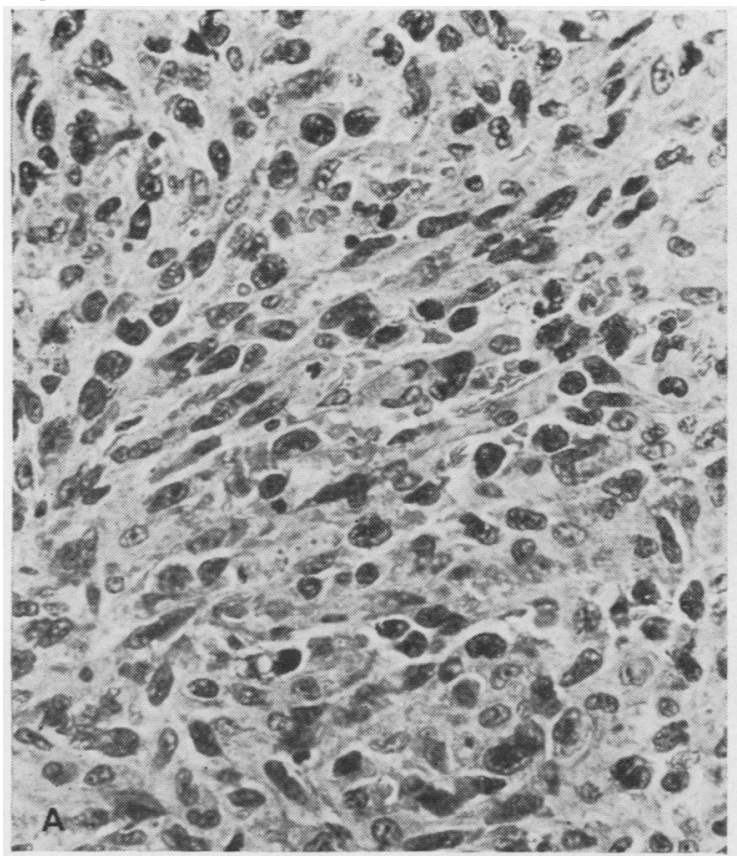

Fig 9
Fig 8 Discrete cell variety hepatocellular carcinoma; cells loosely arranged, in part separated by fibrous tissue with a very mild mononuclear cell infiltrate

(haematoxylin and eosin $\times 250$ )

Fig 9 Anaplastic hepatocellular carcinoma showing: $A$ a predominantly spindle cell appearance and $B a$ distinct epithelial appearance with a poorly defined attempt at acinar formation (haematoxylin and eosin $A$ $\times 250, B \times 300$ )

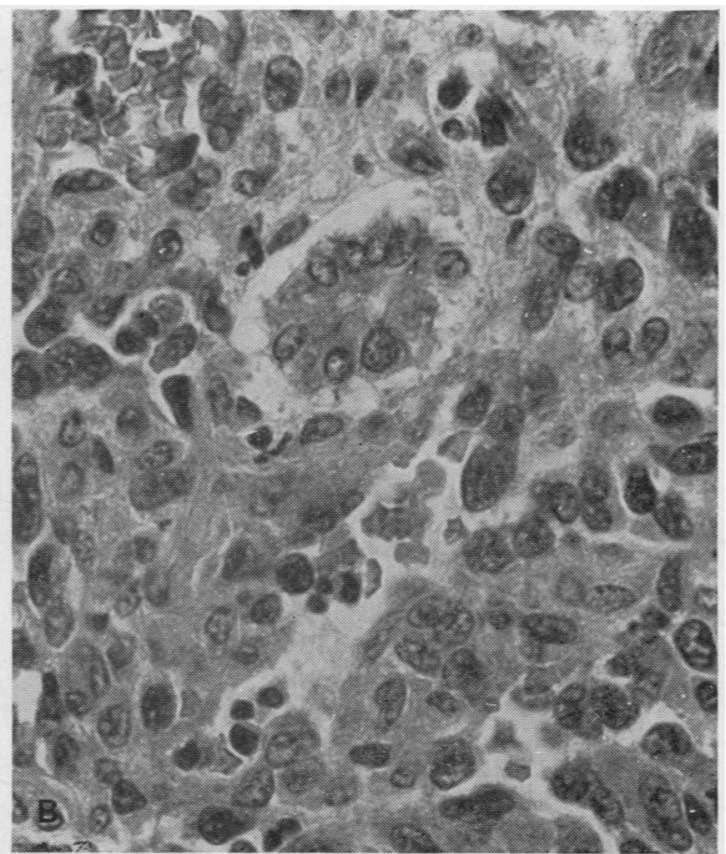




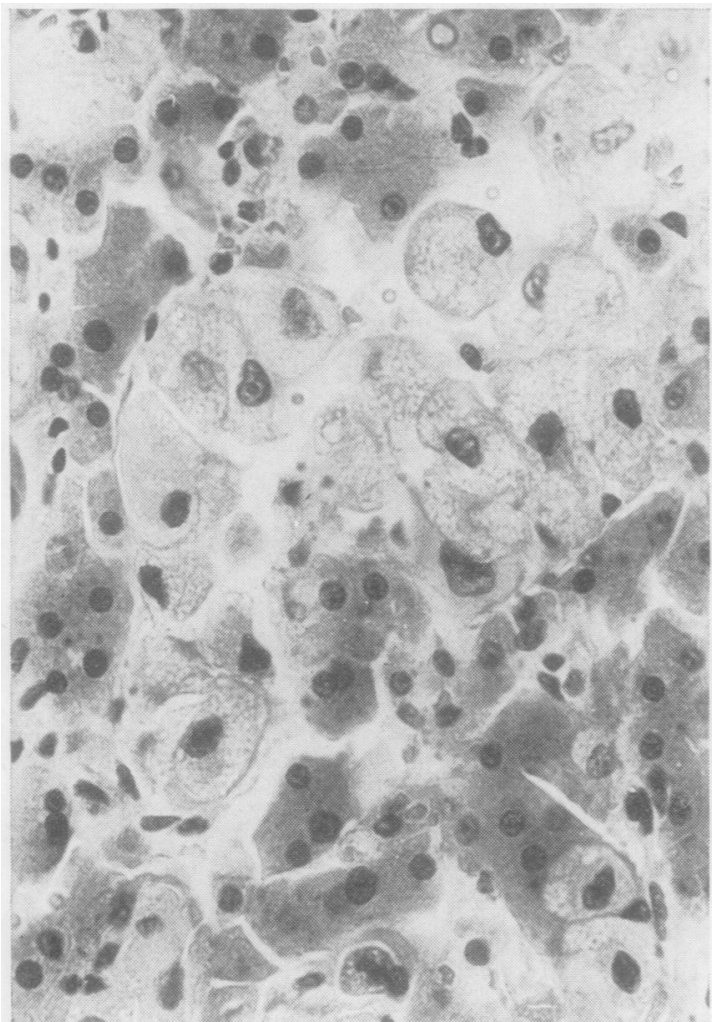

Fig 10

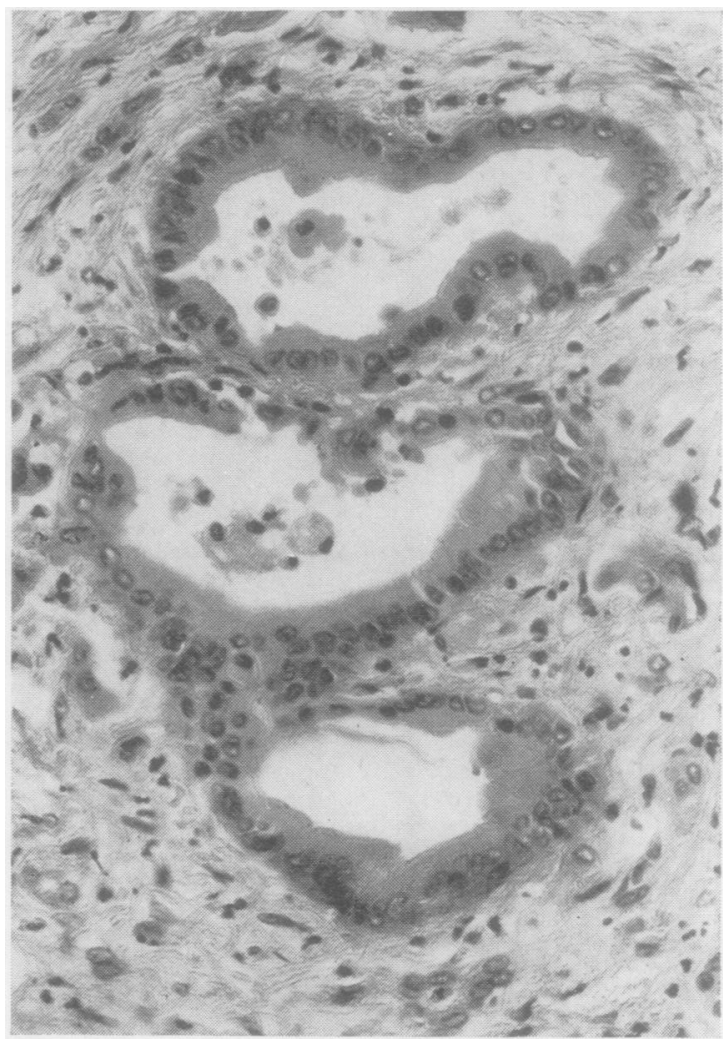

Fig 11

Fig 10 Unusual variant of primary hepatic carcinoma showing large discrete tumour cells with eccentric hyperchromatic nuclei and faintly stained vacuolated cytoplasm: 'possible' adrenal rest tumour (haematoxylin and eosin $\times 300$ ) Fig 11 Well differentiated cholangiocarcinoma showing large acini lined by tall regular columnar epithelium (haematoxylin and eosin $\times 188$ )

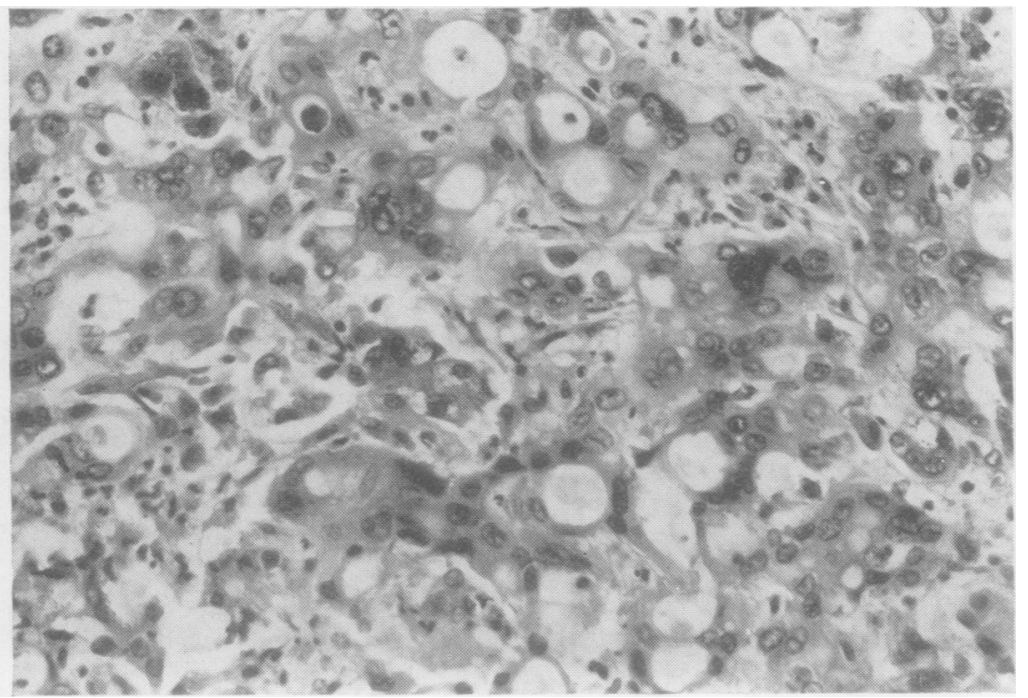

Fig 12 Poorly differentiated cholangiocarcinoma with small irregular acini, and some discrete mucin-containing tumour cells (haematoxylin and eosin $\times 250$ ) 


\begin{tabular}{|c|c|c|c|c|c|c|}
\hline \multirow[t]{2}{*}{ Type } & \multicolumn{2}{|c|}{ Hepatocellular Carcinoma } & \multicolumn{2}{|c|}{ Cholangiocarcinoma } & \multicolumn{2}{|c|}{ Others } \\
\hline & No. & Sex & No. & Sex & No. & Sex \\
\hline $\begin{array}{l}\text { A Cirrhosis present } \\
\text { B Cirrhosis absent }\end{array}$ & $\begin{array}{l}49^{1} \\
15\end{array}$ & $\begin{array}{l}45 \mathrm{M} ; 4 \mathrm{~F} \\
10 \mathrm{M} ; 5 \mathrm{~F}\end{array}$ & $\begin{array}{l}1 \\
7\end{array}$ & $\underset{3 \mathrm{M} ; 4 \mathrm{~F}}{\mathrm{M}}$ & $\begin{array}{l}2^{2} \\
1^{3}\end{array}$ & $\underset{\mathbf{F}}{2 \mathrm{M}}$ \\
\hline Total & 64 & $55 \mathrm{M} ; 9 \mathrm{~F}$ & 8 & $4 \mathrm{M} ; 4 \mathrm{~F}$ & 3 & $2 \mathbf{M}$ \\
\hline
\end{tabular}

Table IV Histological classification of primary hepatic tumours in relation to cirrhosis

${ }^{1}$ In three of these adequate liver tissue not available for assessment but cirrhosis documented in necropsy reports.

${ }^{3}$ Haemangiosarcoma

'Possible' adrenal rest tumour.

Types of hepatocellular carcinoma (A) Trabecular (20), mixed trabecular/acinar (11), compact (13), discrete cell (3), anaplastic (2).

(B) Trabecular (3), mixed trabecular/acinar (2), compact (3), discrete cell (4), anaplastic (3).

spindle-cell aggregates, but with some areas of plump epithelial cells whose resemblance to hepatocytes strongly suggested that these were anaplastic hepatocellular carcinomas (fig 9).

One unusual variant was noted in which the tumour was composed of discrete large oval or polyhedral cells arranged in continuous sheets with here and there very poorly formed acinar structures. There was no evident trabecular arrangement. There was displacement and compression of hepatocytes with extensive intrasinusoidal permeation of the liver by tumour cells. The tumour cells had abundant faintly eosinophilic granular vacuolated PAS-negative cytoplasm (fig 10). There was a low nuclear cytoplasmic ratio, the nuclei tending to be eccentric; some were hyperchromatic but the majority had a loose vesicular pattern with prominent nucleoli. Mitotic figures were few, and there was no evidence of vascular invasion. These appearances were unlike any other primary hepatocellular carcinoma which we have seen and more closely resembled the socalled adrenal rest tumours reviewed by Pendl and Sherlacher (1950) and Edmondson (1958). In the absence of evidence of adrenal hyperfunction in the present case, however, a diagnosis of adrenal rest tumour remains equivocal.

\section{Cholangiocarcinomas}

These varied from well differentiated mucin-secreting adenocarcinomas (fig 11) to tumours in which the acini were small and irregular (fig 12), often with a related scirrhous reaction. They were fairly readily differentiated from the hepatocellular carcinomas, principally on the presence of either intracellular or intraacinar mucin.

\section{Relationship of cirrhosis to tumour types}

The overall incidence of cirrhosis as recorded in the necropsy reports in the 100 cases of hepatic tumours was $64 \%$ (table II). Of the 72 cases personally reviewed, cirrhosis was found in $68 \%$, and the distribution of the various histological tumour types in relation to cirrhosis is summarized in table IV.
Hepatocellular tumours outnumbered cholangiocarcinomas by 8 to 1 , were more common in males then females ( 6 to 1 ), and in $77 \%$ of cases occurred in cirrhotic livers. Cholangiocarcinomas showed no different sex incidence, and cirrhosis was present in only one of eight cases.

\section{Other morphological features}

Bile pigment was seen in 22 of the 75 tumours, occurring within small acini or in canaliculi, predominantly in the mixed trabecular/acinar tumours and less frequently in the pure trabecular variety.

Tumour giant cells were a prominent feature in many cases, varying from moderately large cells with single hyperchromatic nuclei to enormous syncytial or syncytium-like cells with either multiple discrete nuclei or a single large multilobed nucleus (fig 13).

Fatty infiltration of tumour cells was seen in three instances, Mallory's hyaline (fig 14) was noted in three tumours, no such inclusions being present in the normal hepatocytes. None of these cases were alcoholics: in one the patient had had presumed viral hepatitis eight years earlier, and in one the tumour arose in a non-cirrhotic liver. Hyalinized globular intracytoplasmic and/or intranuclear inclusions were seen in 15 tumours.

Premalignant changes were often noted both in cirrhotic nodules and in the parenchyma in noncirrhotic livers. These changes comprised variation in cell size, nuclear hyperchromatism and pleomorphism, occasional mitotic figures, and early disorganization of liver cell cords (fig 15). These changes were particularly noticeable in haemochromatosis, being made more conspicuous by the absence of haemosiderin deposits in the transformed hepatocytes. In the tumours occurring in pigmentary cirrhosis, iron deposits were not found in the tumour cells. Whereas histological evidence of a continuing hepatitis was a well marked feature in most of the livers examined, cellular reaction within tumour cell aggregates was conspicuously absent in most cases. A scanty mononuclear cell infiltrate was present in the discrete cell types of hepatocellular carcinoma 

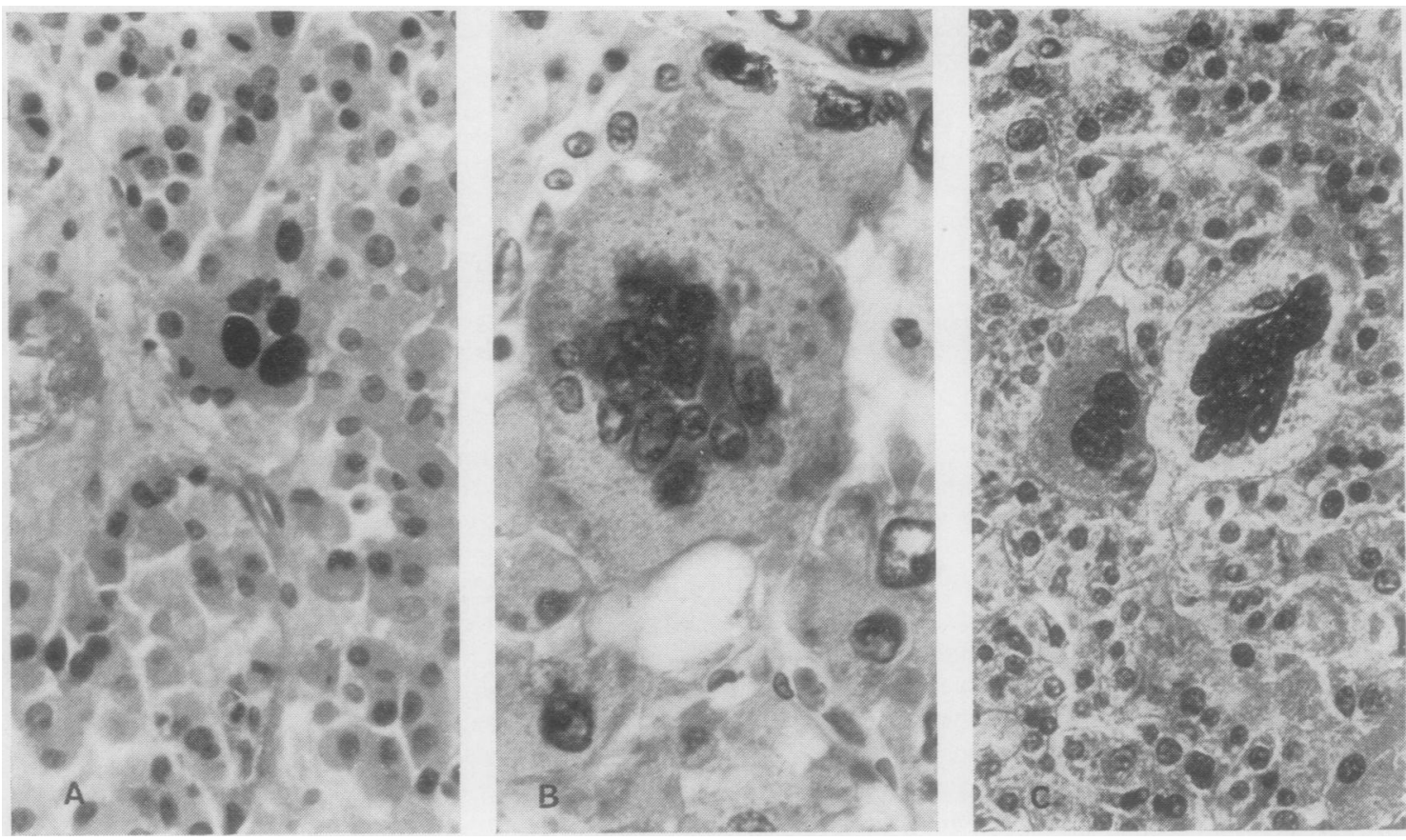

\section{Fig 13}

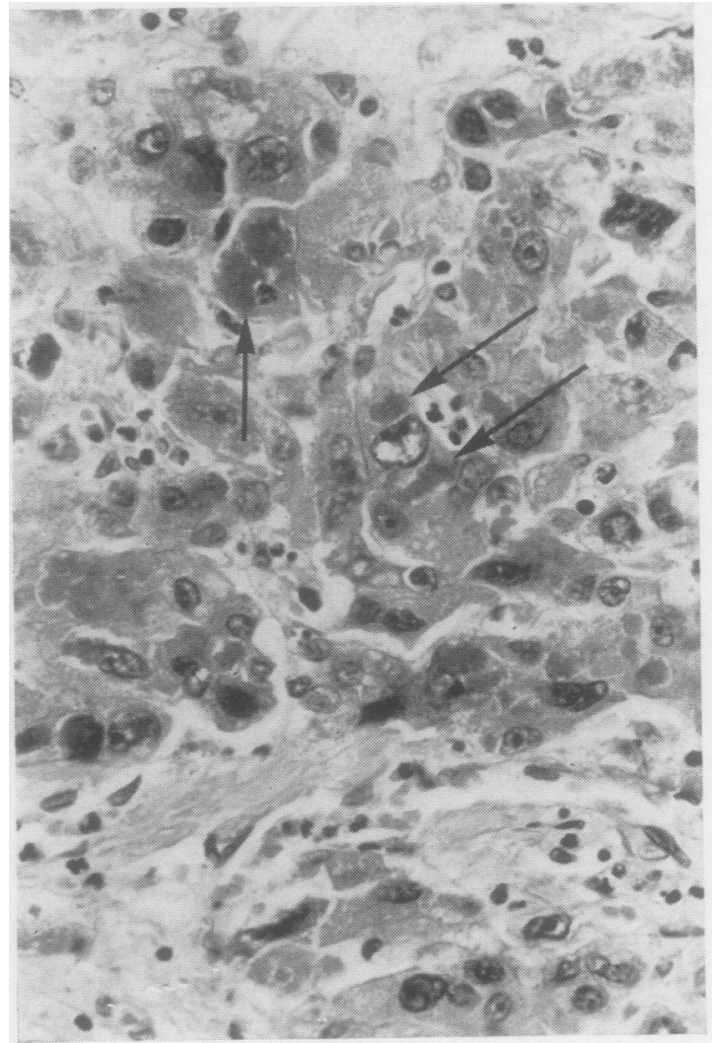

Fig 13 Tumour giant cells: A with single hyperchromatic nuclei; B syncitial with multiple discrete nuclei;

$C$ with single multilobed nucleus

(haematoxylin and eosin: $A$ and $C \times 250, B \times 300$ )

Fig 14 Hepatocellular carcinoma with a number of tumour cells containing Mallory's hyaline (arrowed) (haematoxylin and eosin $\times 300$ ) 


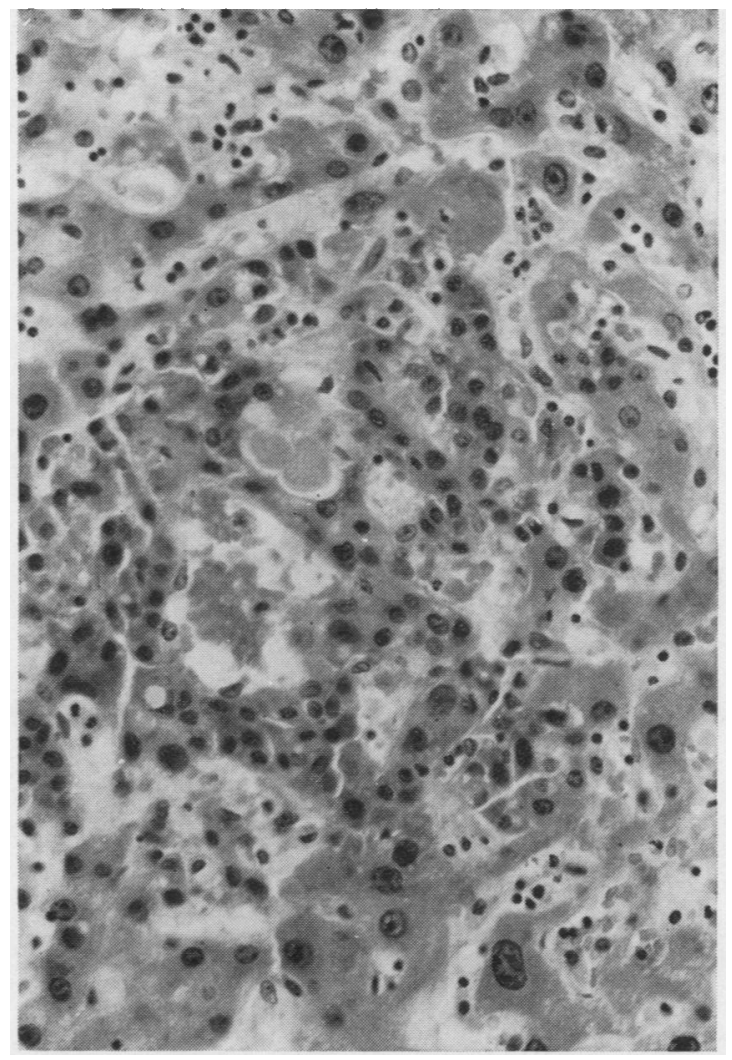

Fig 15 Premalignant change in cirrhotic nodule, with derangement of cell cords, variation in cell size, nuclear hyperchromatism, and mitotic activity

(haematoxylin and eosin $\times 250$ )

(fig 8) and some of the cholangiocarcinomas evoked a scirrhous reaction.

\section{Discussion}

The association of liver carcinoma with cirrhosis has been long recognized, and Sabourin (1881 and 1884, cited by Stewart, 1931) is credited with being the first to suggest that 'multiple nodular hyperplasia might be an intermediate stage between cirrhosis and cancer'. Ewing (1928) and Stewart (1931) stated that cirrhosis was present in over $85 \%$ of hepatocellular carcinomas and in $50 \%$ of cholangiocarcinomas.

There has, however, been considerable and continuing controversy in the literature as to which type of cirrhosis is most commonly associated with malignant change. Confusion in semantics has been common, classification of cirrhosis in some papers being based on possible aetiological factors, alcohol and viral hepatitis, in some on the postmortem morphology of the liver, while in others a combination of these classifications has been used.

Gall (1960a) suggested a more rational pathological differentiation of the various types of cirrhosis into posthepatitic, postnecrotic, and nutritional types. In a subsequent paper (Gall, 1960b) he drew attention to the particular predilection which hepatic tumours had for the posthepatitic and postnecrotic cirrhosis, an observation which, with some exceptions, has been confirmed in subsequent studies (Miyai and Ruebner, 1963; Sagebiel, McFarland, and Taft, 1963; Patton and Horn, 1964; San Jose, Cady, West, Chomet, and Zimmerman, 1965; Mori, 1967; Manderson, Patrick, and Peters, 1968; Takahashi, Orii, and Kaneda, 1968).

In recent years there has been a tendency to introduce a new nomenclature in descriptions of the cirrhotic liver (Scheuer, 1968) and it seems to us that the division into macronodular, micronodular, and mixed patterns has much to recommend it, in that the possible aetiological and pathogenic mechanisms responsible for the evolution of such patterns are not implied in the terminology. Applying the criteria defined by Scheuer, Gall's posthepatitic and postnecrotic types would be classified as macronodular.

Our observations are that primary carcinoma of the liver occurs most frequently against a pattern of macronodular cirrhosis, this being the type seen in 41 of 49 of the present cases. In the remaining eight instances the predominant pattern was also macronodular, but with some micronodular areas. In a geographic survey of cirrhosis Higginson and Svoboda (1970) also note that hepatocellular carcinoma is associated especially with the macronodular type of cirrhosis. It seems likely that the development of cancer reflects the greater propensity for hyperplasia which appears to be a feature of macronodular cirrhosis. The incidence of continuing hepatitis in the present series is also of interest in this context. While the occurrence of a chronic inflammatory cell infiltrate close to the tumour deposits could be considered as evidence of local reaction to tumour growth, the degree and extent of continuing hepatitis in areas of the liver apparently unrelated to tumour deposits was noteworthy. It is possible that it is this continuing destruction of functional liver cell mass which is responsible in part for the development of a macronodular hyperplastic cirrhosis which 'oversteps the normal and takes on the autonomous character of a new growth' (Muir, 1908).

The reported frequency of primary cancer complicating cirrhosis shows considerable geographic differences, and is often more than $40 \%$ in parts of Africa and South East Asia. Popper and Schaffner 
(1957) quote a figure of 2.8 to $6.2 \%$ in North America. Parker (1957) reported a frequency of $16 \cdot 3 \%$ and Elkington, McBrien, and Spencer (1963), $19.1 \%$, both series being from London. Sherlock's experience (1971) is that carcinoma supervenes in $15 \%$ of cirrhotic patients in this country. In the present series the overall frequency is $12 \cdot 2 \%(64 / 525)$ but with notable differences between males and females, 17.3 and $4.4 \%$ respectively.

The obverse relationship, viz, the proportion of tumours accompanied by cirrhosis, has been low in a few series, varying from 21 to $38.5 \%$ (Blatchford, 1952; Thompson, Hackley, and McGinnis, 1957; Nelson, de Elizalde, and Howe, 1966; Nett and Gilbert, 1966). However, the reviews of Berman (1951) and Köhn (1955) indicate that cirrhosis accompanies tumours in $67 \%$ of cases. Our experience is similar, $64 \%$ of the present series having cirrhosis, the association being very much higher with hepatocellular carcinoma $(77 \%)$ than with cholangiocarcinoma (1 in 8) (cf Gustafson, 1937; Greene, 1939; Hoyne and Kernohan, 1947; Edmondson and Steiner, 1954; MacDonald 1957; Glenert, 1961) although Tull's (1932) experience in Singapore was that $66 \%$ of cholangiocarcinomas occurred in cirrhotic livers.

As regards the causal factors in cirrhosis in the present series, the two on which we can comment are alcohol abuse and haemochromatosis. In our experience $18.5 \%$ of local Glasgow cirrhotics have a history of alcohol abuse, ie, 96/520 over the period of review (MacSween and Scott, 1973). Thus the nine alcoholic patients with cirrhosis and liver tumour in this series represent a $9.4 \%(9 / 96)$ tumour incidence in probable alcoholic cirrhosis. Some previous studies have suggested that hepatocellular carcinoma is predominantly associated with alcoholic cirrhosis, occurring in from 18 to $33 \%$ of cases (Edmondson and Steiner, 1954; Parker, 1957; Hällén and Krook, 1963; Lee, 1966; Stone, Islam, and Paton, 1968). These variations may be a reflection of local social habits. In the present series so-called fatty or nutritional cirrhosis, that most commonly associated with alcoholism, was not found in any of the examined material. However, in the terminal stage, fatty/nutritional cirrhosis by a process of necrosis and collapse often comes to resemble postnecrotic or macronodular cirrhosis (Rubin, Krus, and Popper, 1962). Popper and Schaffner (1957), while asserting that cirrhosis as a result of malnutrition or alcoholism is the type most frequently associated with carcinoma, observed that in less advanced fatty cirrhosis in their material the incidence of carcinoma was low (0.5\%). Lee (1966) emphasized that in his cases of alcoholic cirrhosis carcinoma was commonest where the pattern had become 'a coarse nodular cirrhosis', an experience with which we agree. In some African countries where cirrhosis and hepatocellular carcinoma are common, alcohol abuse is not significant, and this would also indicate that ethanol per se has probably no important direct role in hepatocellular carcinogenesis.

We have previously reported on the incidence of liver tumours in haemochromatosis (MacSween and Jackson, 1966). The present figure of tumour in $22 \%$ of haemochromatosis is considerably higher than the $12.2 \%$ of tumour in all cirrhotics, and might appear to indicate an increased risk as has been noted by others (Warren and Drake, 1951; Edmondson and Steiner, 1954). The figure, however, can best be compared with the incidence of tumour in male cirrhotic patients $(17.5 \%)$ since 38 of the 41 haemochromatosis patients were male. The differences then do not achieve statistical significance.

The overall incidence of liver tumours in 21565 necropsies was $0.46 \%$, virtually the same as the $0.47 \%$ found by MacDonald (1957) in a series of 23114 necropsies at the Mallory Institute in Boston over the period $1917-1954$, and close to the $0.53 \%$ found in London by Elkington et al (1963). Over the 70 years of the present study a steady increase in incidence has occurred only since the 1940s (table II). Manderson et al (1968) drew attention to a gradual increase in the incidence of liver carcinoma in the west of Scotland over the period 1949-1965, and to a more abrupt and sustained increase in the Glasgow Royal Infirmary, the other main teaching hospital in this city. In their study they found no corresponding increase in cirrhosis deaths. However, in the present series cirrhosis and tumour have increased in parallel, but the increase in the incidence of tumours has been greater $(0.27$ to $0.52 \%$ of necropsies) than that for cirrhosis $(2.0$ to $3.0 \%$ of necropsies). However, the increase in tumours is entirely due to those tumours occurring in association with cirrhosis.

Glenert (1961) and Ohlsson and Nordén (1965) in Scandinavia and Elkington et al (1963) and Stone et al (1968) in this country found a similar increase in primary carcinoma of the liver but were unable to indicate the reasons. Glenert (1961) could find no evidence that simultaneous cirrhosis was of importance. The evidence, therefore, points to a rising incidence of this tumour, and, whether or not it be related to an accompanying increase in cirrhosis, as the present study suggests, this trend merits further careful epidemiological study.

The male preponderance in primary malignant tumours of the liver is comparable to other reports (Greene, 1939; Wilbur, Wood, and Willett, 1944; MacDonald, 1957), the male incidence in these 
series ranging from 81 to $95 \%$. This difference is, however, confined to hepatocellular carcinomas (86\% in males), cholangiocarcinomas showing an equal sex distribution as noted by MacDonald (1957). There are also marked sex differences in the tumour/cirrhosis index, $17.5 \%$ in males and $4.4 \%$ in females (table I), a feature also noted by Edmondson and Steiner (1954) and by Parker (1957), and indicating a four-fold increased risk of tumour in male cirrhotics. Of tumours complicating cirrhosis $92 \%$ occurred in males, but only $57 \%$ of the non-cirrhotic group were males (table IV). The reasons for these sex differences are not apparent from this study but seem worthy of further investigation.

The mode of presentation, duration of terminal illness, age at death, and the causes of death in the present series were not substantially different from what has been reported by others. Despite growing clinical awareness of the condition, and the possibility of making an early diagnosis by clinical, biochemical, histological, and radiological investigations, there is little evidence to show that the overall course of the disease can be substantially altered (Nelson et al, 1966; El-Domeiri, Huvos, Goldsmith, and Foote, 1971), although some encouraging results have been obtained by partial hepatectomy (Foster, 1970).

In the context of earlier diagnosis the value of serum alpha-fetoprotein estimation continues to receive attention, and it may be that such estimations will prove of value also in screening for high risk liver cell cancer populations (Purves, Branch, Geddes, Manso, and Portugal, 1973).

The $14 \%$ incidence of peptic ulceration in the present series compares with an expected incidence of 4 to $8 \%$ of all hospital necropsies in the United Kingdom (Watkinson, 1960). Active peptic ulceration has been shown to be associated with hepatic cirrhosis. Lipp and Lipsitz (1952) reported ulceration in $19.5 \%$ of cirrhosis cases. MacDonald and Mallory (1958) and Nett and Gilbert (1966) found ulceration in $16 \%$ of patients with primary hepatic carcinoma; Elkington et al (1966) found an even higher frequency when cirrhosis was complicated by tumour $(23 \%$ as compared with $14 \%)$. The possible relationships between the peptic ulceration, deranged metabolism of acid secretion stimulants such as gastrin by the cirrhotic liver, or the inappropriate secretion of such stimulants by liver tumours must remain conjectural.

The considerable morphological variation manifest by hepatocellular carcinomas is well illustrated in the present series of tumours. However, no association of any one particular histological type and any other clinical or pathological parameter was found. In those tumours in which there was a mixed trabecular/acinar pattern, the cells lining the acini closely resembled hepatocytes, and, in distinction to that seen in typical cholangiocarcinomas these acini did not contain mucin. It would seem that these tumours are not mixed hepato/cholangiocarcinomas, and in the present series we were not convinced of any combination tumours in which the adenocarcinomatous areas closely resembled the pattern seen in pure cholangiocarcinomas. The cholangiocarcinomas could be fairly readily distinguished microscopically from hepatocellular carcinomas. In addition they showed differences in sex distribution and in their association with cirrhosis, and we would strongly disagree with Sherlock's views (1971) that microscopically they are little different and that little purpose is served in distinguishing between them.

\section{References}

Berman, C. (1951). Primary Carcinoma of the Liver: A Study in Incidence, Clinical Manifestations, Pathology and Aetiology. Lewis, London.

Berman, C. (1958). Primary carcinoma of the liver. Advanc. Cancer Res., 5, 55-96.

Blatchford, F. W., Jr. (1952)- Primary carcinoma of the liver: a critical analysis of sixteen cases. Gastroenterology, 21, 238-244.

Edmondson, H. A. (1958). Tumors of the Liver and Intra-Hepatic Bile Ducts. (Atlas of Tumor Pathology, Sect. VII, Fasc. 25.) Armed Forces Institute of Pathology, Washington, D.C.

Edmondson, H. A., and Steiner, P. E. (1954). Primary carcinoma of the liver; study of 100 cases among 48,900 necropsies. Cancer (Philad.), 7, 462-503.

El-Domeiri, A. A., Huvos, A. G., Goldsmith, H. S., and Foote, F. W. (1971). Primary malignant tumors of the liver. Cancer (Philad.), 27, 7-11.

Elkington, S. G., McBrien, D. J., and Spencer, H. (1963). Hepatoma in cirrhosis. Brit. med. J., 2, 1501-1503.

Ewing, J. (1928). Neoplastic Diseases: A Treatise on Tumors, 3rd ed., p. 721. Saunders, Philadelphia and London.

Foster, J. H. (1970). Survival after liver resection for cancer. Cancer (Philud.), 26, 493-502.

Gall, E. A. (1960a). Posthepatitic, postnecrotic and nutritional cirrhosis: a pathologic analysis. Amer. J. Path., 36, 241-271.

Gall, E. A. (1960b). Primary and metastatic carcinoma of the liver. Arch. Path., 70, 226-232.

Glenert, J. (1961). Primary carcinoma of the liver: a post mortem study of 104 cases. Acta path. microbiol. scand., 53, 50-60.

Greene, J. M. (1939). Primary carcinoma of the liver: a 10 year collective review. Surg. Gynec. Obstet., 69, 231-236.

Gustafson, E. G. (1937). An analysis of 62 cases of primary carcinoma of the liver based on 24,400 necropsies at Bellevue Hospital. Ann. intern. Med., 11, 889-900.

Hällén, J., and Krook, H. (1963). Follow-up studies on an unselected ten-year material of 360 patients with liver cirrhosis in one community. Acta med. scand., 173, 479-493.

Higginson, J. (1963). The geographical pathology of primary liver cancer. Cancer Res., 23, 1624-1633.

Higginson, J., and Svoboda, D. J. (1970). Primary carcinomas of the liver as a pathologist's problem. In Pathology Annual, Vol. 5, edited by Sheldon C. Sommers, p. 61. Butterworths, London.

Hoyne, R. M., and Kernohan, J. W. (1947). Primary carcinoma of the liver. A study of 31 cases. Arch. intern. Med., 79, 532-554.

Köhn, K. (1955). Der primäre Leberkrebs. Springer, Berlin.

Lee, F. I. (1966). Cirrhosis and hepatoma in alcoholics. Gut, 7, 77-85.

Lipp, W. F., and Lipsitz, M. H. (1952). The clinical significance of the coexistence of peptic ulcer and portal cirrhosis, with special reference to the problem of massive hemorrhage. Gastroenterology, 22, 181-191.

MacDonald, R. A. (1957). Primary carcinoma of the liver: a clinicopathologic study of one hundred and eight cases. Arch. intern. Med., 99, 266-279. 
MacDonald, R. A., and Mallory, G. K. (1958). The natural history of postnecrotic cirrhosis. Amer. J. Med., 24, 334-357.

MacSween, R. N. M., and Jackson, J. M. (1966). Haemochromatosis a clinico-pathological review of 37 cases. Scot. med. J., 11, 395-400.

MacSween, R. N. M., and Scott, A. R (1973). Hepatic cirrhosis: a clinico-pathological review of 520 cases. J. clin. Path., 26, 936-942.

MacSween, R. N. M., Vetters, J. M., Ross, Sheila K., Ferguson, J., Johnstone, J. M., and Sandison, A. T. (1973). Haemangioendothelial sarcoma of the liver. J. Path., 109, 39-44.

Manderson, W. G., Patrick, R. S., and Peters, Elizabeth E. (1968). Incidence of primary carcinoma of the liver in the West of Scotland between 1949 and 1965. Gut, 9, 480-484.

Miyai, K., and Ruebner, B. H. (1963). Acute yellow atrophy, cirrhosis and hepatoma. Arch. Path., 75, 609-617.

Mori, W. (1967). Cirrhosis and primary cancer of the liver: comparative study in Tokyo and Cincinnati. Cancer (Philad.), 20, 627-631.

Muir, R. (1908). On proliferation of the cells of the liver. J. Path. Bact., $12,287-305$

Nelson, R. S., de Elizalde, R., and Howe, C. D. (1966). Clinical aspects of primary carcinoma of the liver. Cancer (Philad.), 19, 533-537.

Nett, A. E., and Gilbert, J. A. L. (1966). Primary carcinoma of the liver in Alberta. Canad. med. Ass. J., 95, 45-49.

Ohlsson, E. G. H., and Nordén, J. G. (1965). Primary carcinoma of the liver: a study of 121 cases. Acta path. microbiol. scand., 64, 430-440.

Parker, R. G. F. (1957). The incidence of primary hepatic carcinoma in cirrhosis. Proc. roy. Soc. Med., 50, 145-147.

Patton, R. B., and Horn, R. C., Jr. (1964). Primary liver carcinoma: autopsy study of 60 cases. Cancer (Philad.), 17, 757-768.

Pendl, O., and Sherlacher, A. (1950). Uber einen Fall von Hypernephrom der Leber. Öst. Z. Kinderheilk, 4, 269-279.
Popper, H., and Schaffner, F. (1957). In Liver: Structure and Function, p. 593. Grune and Stratton, New York and London.

Purves, L. R., Branch, W. R., Geddes, E. W., Manso, C., and Portugal, M. (1973). Serum alpha-feto-protein. VII. The range of apparent serum values in normal people, pregnant women, and primary liver cancer high risk populations. Cancer (Philad), 31, 578-587.

Rubin, E., Krus, S., and Popper, H. (1962). Pathogenesis of postnecrotic cirrhosis in alcoholics. Arch. Path., 73, 288-299.

Sagebiel, R. W., McFarland, R. B., and Taft, E. B. (1963). Primary carcinoma of the liver in relation to cirrhosis. Amer. J. clin. Path., 40, 516-520.

San Jose, D., Cady, A., West, M., Chomet, B., and Zimmerman H. J. (1965). Primary carcinoma of the liver. Analysis of clinical and biochemical features of 80 cases. Amer. J. dig. Dis., 10, 657-674.

Scheuer, P. J. (1968). Liver Biopsy Interpretation, p. 55. Baillière, Tindail, and Cassell, London.

Sherlock, S. (1971). Diseases of the Liver and Biliary System; 4th ed. revised 3rd printing, p. 651. Blackwell, Oxford.

Stewart, M. J. (1931). Precancerous lesions of the alimentary tract. Lancet, 2, 565-572.

Stone, W. D., Islam, N. R. K., and Paton, A. (1968). The natural history of cirrhosis: experience with an unselected group of patients. Ouart. J. Med., 37, 119-132.

Takahashi, T., Orii, T., and Kaneda, M. (1968). Precancerous condition of the human liver. Tohoku J. exp. Med., 94, 203-224.

Thompson, D. J., Hackley, D. J., and McGinnis, C. M. (1957). Primary carcinoma of the liver. J. chron. Dis., 6, 205-219.

Tull, J. C. (1932). Primary carcinoma of the liver: a study of 134 cases. J. Path. Bact., 35, 557-562.

Warren, S., and Drake, W. L., Jr. (1951). Primary carcinoma of the liver in hemochromatosis. Amer. J. Path., 27, 573-609.

Watkinson, G. (1960). The incidence of chronic peptic ulcer found at necropsy. Gut, 1, 14-30.

Wilbur, D. L., Wood, D. A., and Willet, F. M. (1944). Primary carcinoma of the liver. Ann. intern. Med., 20, 453-485. 